\title{
NOTÍCIA
}

\author{
Pablo Álvarez Domínguez \\ Universidad de Sevilla \\ pabloalvarez@us.es
}

\section{LA REVISTA CABÁS, PREMIO COSSÍO, 2020}

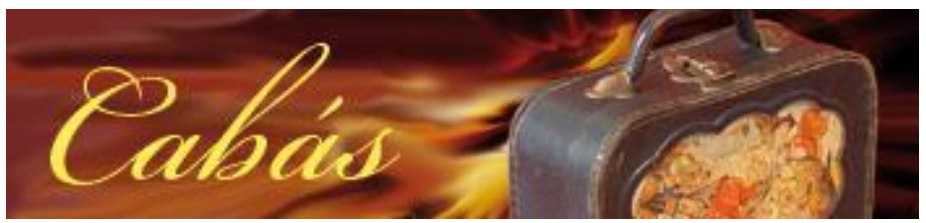

$\begin{array}{rrr}\text { La } & \text { Revista } & \text { Cabás, } \\ \text { Patrimonio } & \text { Histórico } & \text { Educativo } \\ \text { (http://revista.muesca.es/), } & \text { editada }\end{array}$

por el CRIEME (Centro de Recursos, Interpretación y Estudios de la Escuela), de Polanco (Cantabria-España, ha sido galardonada con el Premio de Patrimonio Histórico Educativo "Manuel Bartolomé Cossío", 2020, otorgado por la Sociedad Española para el Estudio del Patrimonio Histórico Educativo (SEPHE) https://sephe.org/premio-manuel-bartolome-cossio2020-patrimonio-historico-educativo/. El Premio fue entregado por el Presidente de la Sociedad, D. Luís Mª Naya Garmendía, al director de la Revista, D. José Miguel Sáiz Gómez, en el marco de las IX Jornadas de la SEPHE celebradas en Málaga en septiembre de 2021.

El Jurado ha considerado que la candidatura reunía méritos relevantes como: la aportación hecha durante una década al conocimiento, difusión y valoración del patrimonio histórico-educativo, que ha conformado ya una trayectoria dilatada y consolidada; su carácter pionero en este ámbito, y original en el formato digital, que ha favorecido su difusión y accesibilidad; $y$, finalmente, su enfoque editorial, que combina de forma estimable el rigor científico con el valor divulgativo y motivador.

La Sociedad Española para el Estudio del Patrimonio Histórico-Educativo (S.E.P.H.E), con la colaboración del Instituto del Patrimonio Cultural de España, convoca anualmente el PREMIO MANUEL BARTOLOMÉ COSSÍO, atendiendo a estas dos modalidades:

a) Dirigida a impulsar y valorar las iniciativas y trabajos que -desde la dedicación a ese ámbito- hayan concurrido, durante el periodo indicado en estas bases, al desarrollo de la que constituye su fundamental finalidad: la protección, conservación, estudio e investigación del patrimonio histórico-educativo, así como la promoción de acciones que estimulen tales tareas. 
b) Dirigida a premiar trayectorias históricas consolidadas y reconocidas, tanto de entidades como de personas, en el ámbito de la protección, conservación, estudio y difusión del patrimonio histórico-educativo.

El Premio Manuel Bartolomé Cossío pretende, al mismo tiempo, rendir un homenaje al primer Director del Museo Pedagógico Nacional (1882-1941) y primer Catedrático de Pedagogía de la Universidad española, el institucionista Manuel Bartolomé Cossío (Haro, La Rioja, 1857 - Collado Mediano, Madrid, 1935). Con estas perspectivas el Premio tiene un carácter honorífico, para enaltecer y agradecer esfuerzos y méritos. Su acreditación y entrega se realizará en tiempo y forma, previamente anunciado por la SEPHE.

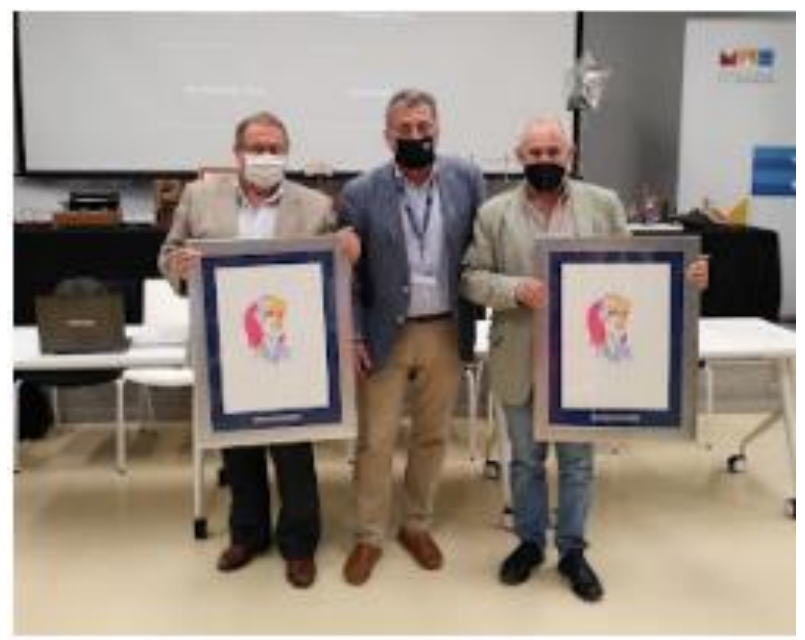

En el centro, D. Luis María Naya Garmendia, presidente de la SEPHE. A la derecha, D. José Miguel Sáiz Gómez, director de la Revista Cabás, Premio Cossío. A la izquierda, D. José María Hernández Díaz, también premiado. En las IX Jornadas de la SEPHE, Málaga, 2021. 